\section{Section 5 (2)}

DeAr SiRS

D. I. Khoosal (Psychiatric Bulletin, May 1992, 16, 312) discussed implementing a Section 5 (2) to transfer a patient from a NHS owned psychiatric nursing home to a hospital. If the home is a "hospital" or has the appropriate registration as a "nursing home", detention is possible under the Mental Health Act. In our district, in response to a similar situation, the MHA commission confirmed that a patient can be transferred under Section 5 (2).

Hence, what Dr Khoosal proposed may be legally "possible" but not necessarily optional for the patient: although not having the same consequences as an Assessment or Treatment Order, Section 5 (2) restricts the patient and is followed by medical and social service examinations with a view to implementing them. Consideration should be given to the interests of the patient, who would have the benefit of three opinions, rather than one, for a Section 2 or 3 to be initiated in the first instance, assuming these may be obtained expediently.

Halton General Hospital

C. BRABBINS

Runcorn

Cheshire WA7 2DA

\section{"Cannabis psychosis"}

DeAR Sirs

Dr Eva (Psychiatric Bulletin, May 1992, 16, 310-311)

predicts that the nosological status of "cannabis psychosis" will soon become clear. The relationship between cannabis and psychotic conditions is complex. An acute toxic confusional state following ingestion is well documented and probably dosedependent, except in a few individuals who develop an idiosyncratic psychotic reaction at low doses. First time users may also be more susceptible. An acute psychosis in clear consciousness with schizophreniform or mania-like features can also occur. Clinical data on the role of cannabis in the aetiology of more persistent paranoid or affective disorders are sparse. That established schizophrenics use the drug is well recognised and may represent self-medication. One group of investigators has claimed to show that cannabis use is an independent risk factor for the development of schizophrenia (Andreasson et al, 1987).

It is hardly true to say that the entity of cannabis psychosis is eschewed in the literature. There have been many papers on the subject since American researchers began taking interest in response to the drug's widespread use there in the late 1960s. What is still not clear is which of the several interactions between the drug and psychotic illness is referred to by "cannabis psychosis". Because of this confusion the term is best avoided.

\section{St Tydfil's Hospital}

Huw Thomas

Merthyr Tydfil

Mid-Glamorgan, Wales

\section{References}

Andreasson, S., Allebeck, P. \& Engstrom, A. (1987)

Cannabis and schizophrenia: a longitudinal study of Swedish conscripts. Lancet, ii, 1483-1485.

\section{Out-patient non-attenders}

DeAR SIRS

I read with interest the letter from Drs Hellewell \& Pugh (Psychiatric Bulletin, May 1992, 16, 306) in which they report the findings of a case-controlled study of new out-patient non-attenders. The authors suggest that it is possible to predict non-attendance at the first out-patient appointment on the basis of an analysis of the GP's referral letter. While I accept that there is considerable variation in the quality of these letters, my own data from a larger sample contradicts the view that differences in standards of communication from GPs is reflected in non-attendance. I believe that the way in which Drs Hellewell \& Pugh present their findings from this important area of research is potentially misleading.

I studied 100 consecutive GP referrals of catchment area patients to the Maudsley Hospital Outpatient Department, of whom 74 were referred to out-patient clinics and 26 to the emergency clinic. The non-attendance rate among the former was $33.8 \%$ (95\% confidence interval 23.0 to $44.6 \%$ ). Nonattendance at the first appointment was not associated with patients' age, marital status, ethnicity of home-ownership, though the unemployed were less likely to keep appointments than those in work (non-attendance rate $41.8 \%$ v $17.9 \%, P=0.06$ ).

Among this sample there were no associations between non-attendance and any features of the referral itself. In particular, non-attendance was not predicted by the omission of the reason for, or expected outcome of, specialist referral from the GP's letter. Furthermore, there were no differences between attenders and non-attenders in terms of the quality of referral letters as defined by legibility, information content or diagnostic development.

I accept that there may be differences in GP referrals and patient behaviour between Manchester and Camberwell, though these are unlikely to explain the clear differences in our findings. In my view these are more likely to be methodological in origin, and I am especially surprised that the investigators found such strong statistical associations from such a small sample of patients. 
Like Drs Hellewell \& Pugh I deplore the waste of resources implicit in a non-attendance rate of over $30 \%$. In the present resource-starved climate this state of affairs cries out for remedial action. Nevertheless, the strongest association with non-attendance reported by the authors was with a failure by patients to confirm their appointment. However revealing this might be, it is not a feature of the referral process itself and in combining this with the latter in a regression analysis they overstate the case for scrutinising referral letters routinely as a means of improving efficiency.

PRiSM Team

S. R. WEICH

Institute of Psychiatry

London SE5 8 AF

\section{Reply}

\section{DeAR SirS}

Our study was carried out as a practical response to the problem of non-attendance at our new patient clinic. It is a small study, although we do not accept that there are major methodological shortcomings and the statistical treatment is, we consider, entirely appropriate for the data. Our findings are not only statistically significant but also of practical relevance. It may also be of interest to note that, unlike Dr Weich, our colleagues expressed no surprise at our findings.

In an examination of new patient non-attendance it is necessary to examine the whole process of referral, from individuals first consulting their doctor to their eventual presentation at the clinic. As it was our practice to request confirmation from our patients of their intention to attend then it is entirely appropriate that this element be included in the regression analysis.

Clearly, there is a need for further research into this problem. We are shortly to begin a more comprehensive prospective study; however, until newer findings are available, we would commend to readers our earlier suggestion that those patients likely not to attend may be identified with some reliability by requesting confirmation from patients and examining their referral letters.

West Didsbury, Manchester M20 8LR

\section{Diogenes syndrome}

DeAR Sirs

I read Dr Coakleys letter (Psychiatric Bulletin, February 1992,16,111) surprised that in the context of depression he is so prepared to devolve responsibility for self neglect to the housing department and public health. Ignoring a mental disorder in favour of a description of a patient's domestic chaos receives no professional credibility or sanction by calling it the Diogenes syndrome.

Dr Coakley seems to believe that self neglect and mental illness are mutually exclusive categories. In MacMillan \& Shaw's (1966) seminal paper on senile squalor, over $50 \%$ suffered from psychoses, mainly dementias, chronic paranoid schizophrenia and manic depression. Of the "normals" $32 \%$ had "reactive depression", 58\% "grief" and 32\% clearly developed after bereavement; $15 \%$ were severely immobile, $29 \%$ severely deaf and $20 \%$ blind or visually impaired. Clarke et al (1975), who coined the term Diogenes syndrome, selected their sample on the basis of acute medical presentations and found $50 \%$ to be suffering from mental disorders, mainly dementias and schizophrenia, with multiple nutritional deficiencies and severe physical illness.

The diagnostic and prognostic heterogeneity of Diogenes labelled patients makes the term of limited value (Cybulska \& Rucinski, 1986). Though patients often do badly after hospitalisation, possibly because they are so ill by this time (Cybulska \& Rucinski, 1986), Roe (1987) discharged 16 of a 25 patient sample with 9 returning to their own homes "where they lived reformed lives". Clarke et al (1975) discharged 13 of 30 patients with 5 returning home and 8 settling into residential homes "with no regrets".

The use of a catchy, eponymous description of people's inability to care for themselves while mentally ill is of no value to psychiatrists on their patients. The patient described in our letter (Psychiatric Bulletin, 1991, 15. 574) was re-admitted within three month of discharge with persecutory delusions and threatening behaviour toward her neighbours. She is currently receiving ECT under section 58. Digoenes was not able to help.

Fazakerly Hospital

D. N. ANDERSON

Liverpool L9 7AL

\section{References}

Clarke, A. N. G. Mankikar, G. D. \& Gray, I. (1975) Diogenes syndrome: A clinical study of gross neglect in old age. Lancet, i, 366-368.

Cybulska, C. \& Rucinski, J. (1986) Gross self neglect in old age. British Journal of Hospital Medicine, 36, 21-24.

MacMillan, D. \& Shaw, P. (1966) Senile breakdown in standards of personal and environmental cleanliness. British Medical Journal, ii, 1032-1037.

RoE, P. F. (1987) Self neglect or chosen lifestyle. British Journal of Hospital medicine, 37, 83-84. 